Santos, LHA, Carvalho, DF, Silva, AFG \& Rossetto, HHP. (2020). Blended learning: pratical experience in the classroom. Research, Society and Development, 9(7): 1-13, e462974332.

\title{
Ensino híbrido: experiência prática em sala de aula
}

Blended learning: pratical experience in the classroom

Enseñanza híbrida: experiencia práctica en el aula

Recebido: 08/05/2020 | Revisado: 10/05/2020 | Aceito: 13/05/2020 | Publicado: 22/05/2020

Luiz Henrique Alves dos Santos

ORCID: https://orcid.org/0000-0003-3117-6407

Universidade Pitágoras Unopar, Faculdade Anhanguera de Brasília, Brasil

E-mail: luiz.fenis@gmail.com

Diego Fogaça Carvalho

ORCID: https://orcid.org/0000-0002-4984-6344

Universidade Pitágoras Unopar, Universidade Anhanguera Uniderp, Brasil

E-mail: diegofocarva@gmail.com

Angélica da Fontoura Garcia Silva

ORCID: https://orcid.org/0000-0002-2435-9240

Universidade Pitágoras Unopar, Universidade Anhanguera de São Paulo, Brasil

E-mail: angelicafontoura@gmail.com

Hallynnee Héllenn Pires Rossetto

ORCID: https://orcid.org/0000-0002-2063-580X

Universidade Pitágoras Unopar e Universidade Estadual de Londrina, Brasil

E-mail: hallynneerossetto@gmail.com

\section{Resumo}

Este artigo tem por objetivo analisar como se constituíram os processos interativos envolvendo professor, aluno e conteúdo em uma disciplina desenvolvida no modelo de Ensino Híbrido, conhecido como sala de aula invertida. O estudo foi realizado em um curso de Administração, especificamente na disciplina Ética, Política e Sociedade. Por meio da observação participante, foi possível analisar, nas aulas, a constituição do processo de aprendizagem, a interação do professor com os alunos quando resolviam uma situaçãoproblema da disciplina. Pôde-se identificar, ainda, comparando com o modelo tradicional de 
ensino, que o aluno passa a ser o centro do processo de ensino e aprendizagem e o professor, muitas vezes, configura-se um orientador do caminho que o aluno precisa percorrer.

Palavras-chave: Ensino híbrido; Interação aluno-professor; Ensino de administração.

\begin{abstract}
This article has to analyze how interactive processes involving teacher, student and content were constituted in a discipline, developed in a blended learning model, known as inverted classroom. Such study was carried out in a course of Administration, specifically in the discipline Ethics, Politics and Society. Through participant observation, it was possible to analyze in class how the learning process was constituted, the interaction of the teacher's activity with the students when they solved a problem situation of the discipline. It was possible to identify, comparing with the traditional teaching model, that the student becomes the center of the teaching and learning process and the teacher, many times, is configured as an advisor on the path that the student needs to go.
\end{abstract}

Keywords: Blended learning; Student-teacher interaction; Administration teaching.

\title{
Resumen
}

Este artículo tiene como objetivo analizar cómo los procesos interactivos que involucran al maestro, el alumno y el contenido se constituyeron en una disciplina, desarrollada en un modelo de enseñanza híbrido, conocido como aula invertida. Dicho estudio se realizó en un curso de Administración, específicamente en la disciplina Ética, Política y Sociedad. A través de la observación participante, fue posible analizar en clase cómo se constituyó el proceso de aprendizaje, la interacción de la actividad del maestro con los estudiantes cuando resolvieron una situación problemática de la disciplina. Fue posible identificar, en comparación con el modelo de enseñanza tradicional, que el alumno se convierte en el centro del proceso de enseñanza y aprendizaje y que el maestro, muchas veces, se configura como un asesor en el camino que el alumno debe seguir.

Palabras clave: Enseñanza Híbrida, Interacción Alumno-Profesor, Enseñanza administrativa.

\section{Introdução}

Este artigo tem por objetivo analisar e apresentar como se configuraram as relações entre alunos e professor em aulas pautadas no ensino híbrido, em uma pesquisa desenvolvida na disciplina de Ética, Política e Sociedade ministrada no curso de Administração. Essa 
modalidade de ensino está se tornando uma referência pelo fato de alinhar situações de ensino via plataformas digitais, a distância, e encontros presenciais, explorando as novas habilidades advindas da introdução das tecnologias digitais na vida dos seres humanos. Segundo Bergmann \& Sams (2016), o conceito de sala de aula invertida pode ser entendido como a divisão do tempo de aprendizagem do aluno na sala presencial com as plataformas digitais que são acessadas em outros ambientes.

[...] essa mescla entre a sala de aula e ambientes virtuais é fundamental para abrir a escola para o mundo e, também, trazer o mundo para dentro da instituição. Outra mescla é aquela entre os processos de comunicação mais planejados, organizados e formais e outros mais abertos, como o que acontece nas redes sociais, em que há uma linguagem mais familiar, maior espontaneidade e fluência constante de imagens, ideias e vídeos (Bacich, Tanzi \& Trevisani, 2015, p.39).

Participamos das aulas de um curso de Bacharelado em Administração, especificadamente na disciplina Ética, Política e Sociedade, na qual os alunos tiveram o conteúdo ministrado por meio da plataforma digital e em sala de aula presencial.

No ensino híbrido, os alunos, em um primeiro momento, estudam em qualquer espaço físico em que haja conectividade com a Internet, individual ou em grupo, e em qualquer horário. Em sala de aula presencial, junto com o professor, discutem o conteúdo por meio de situações-problemas e desenvolvimento de projetos, buscando, em conjunto, solucioná-las aplicando os conhecimentos já adquiridos (Bergmann \& Sams, 2016).

No decorrer do artigo, a experiência dessa configuração do ensino híbrido é descrita e analisada. A coleta de dados se deu por meio das observações e anotações da aula, nas quais foram destacados as atitudes e os depoimentos dos alunos e do professor diante desse processo de ensino.

$\mathrm{Na}$ sequência, são apresentadas algumas considerações sobre o Ensino Híbrido, contextualizando a pesquisa do ponto de vista teórico e, em seguida, são apresentados os procedimentos metodológicos, os relatos e as análises.

\section{Ensino Híbrido: breves apontamentos}

Ibidem (2016) relatam que os alunos atualmente crescem com acesso à Internet, aoYoutube, Facebook e a muitos outros recursos advindos do avanço tecnológico digital ocorrido nas últimas décadas. O crescimento do ensino on-line tem se intensificado nos 
últimos anos, fazendo-se presente na vida das pessoas, proporcionando experiências que se configuraram indispensáveis para viver, como a troca de mensagens instantâneas, via aplicativos nos smartphones, previsão do tempo, rotas em viagens.

Diante desse contexto, a educação não se manteve isenta, o processo de ensino e aprendizagem adquiriu novas ferramentas, proporcionando a construção de modelos em que se mesclou o ensino on-line com o ensino presencial, o que pode ser considerado como uma maneira de se configurar o Ensino Híbrido (EH).

[...] o ensino híbrido é um programa de educação formal no qual um aluno aprende, pelo menos em parte, por meio do ensino on-line, com algum elemento de controle do estudante sobre o tempo, lugar, modo e/ou ritmo do estudo, e pelo menos em parte em uma localidade física supervisionada fora de sua residência (Christensen, Horn \& Staker, 2013, p.31).

O EH é conhecido em determinados setores educacionais como Blended Learning, em inglês. Christensen, Horn \& Staker (2013) consideram que, nesse modelo de ensino, o aluno aprende de uma forma diferente do modelo que se instituiu nas escolas no século passado e que continua, ainda que fragmentado, nas práticas atuais, conhecido por modelo tradicional. No Ensino Híbrido, o protagonismo da aprendizagem passa a ser do aluno e não mais somente do professor, transferindo-se o aprendiz para o centro do processo de ensino e aprendizagem.

Segundo Albino \& Reinhard (1998), no ensino presencial, existem interações entre o educador e o educando em um local estabelecido, como padrão, a sala de aula. Nesse encontro, ocorre a atividade de ensinar e aprender. $\mathrm{O}$ educador configura-se, em alguns momentos, como o transmissor do saber, e criam-se os conteúdos para assegurar que sejam entendidos pelos alunos no encontro ou diálogo. O educador é o organizador do espaço no qual serão realizadas as experiências que propiciam a aprendizagem. Na Educação a Distância, a interação entre educador e educando acontece de forma indireta, mediante os meios disponibilizados pela tecnologia. A metodologia deve fazer com que todos os materiais sejam organizados de forma que os educandos tenham condição de aprender de forma autônoma.

Bacich, Tanzi \& Trevisani (2015) afirmam que, no meio da educação, existem vários tipos de blended (misturas), ou educação híbrida, de saberes e valores, quando assimilamos várias áreas de conhecimento, de metodologias, com desafios, atividades, projetos, games, grupais ou individuais, colaborativos ou personalizados. Os autores citados organizam essa mistura de acordo com os modelos abaixo: 
Research, Society and Development, v. 9, n. 7, e462974332, 2020

(CC BY 4.0) | ISSN 2525-3409 | DOI: http://dx.doi.org/10.33448/rsd-v9i7.4332

- Modelo de rotação: os estudantes revezam as atividades realizadas de acordo com um horário fixo ou orientação do professor, dividindo-se em quatro processos, a rotação por estações, laboratório rotacional, sala de aula invertida e rotação individual.

- Modelo flex: os alunos também têm uma lista a ser cumprida, com ênfase no ensino on-line.

- Modelo à la carte: o estudante é responsável pela organização de seus estudos, de acordo com os objetivos gerais a serem atingidos, organizados em parceria com o educador.

- Modelo virtual enriquecido: trata-se de uma experiência realizada por toda a escola, em que, em cada disciplina (como a de matemática, por exemplo), os alunos dividem seu tempo entre a aprendizagem on-line e a presencial (Bacich, Tanzi \& Trevisani, 2015, p.54).

A plataforma digital, na qual está inserida o modelo do ensino híbrido, é um ambiente virtual de aprendizagem, indicado, na maioria dos centros universitários, pela sigla AVA. Nele, os professores têm acesso diferenciado dos alunos, portanto é enviado pelos docentes conteúdos referentes às disciplinas que serão estudadas, como vídeos, textos, artigos, situação-problema, atividades, projetos, dentre outros. Bacich, Tanzi \& Trevisani (2015, p.41) destacam que,

[...] as escolas mais conectadas podem integrar melhor a sala de aula, os espaços da escola e do bairro e os ambientes virtuais de aprendizagem. Podem disponibilizar as informações básicas de cada assunto, atividade ou projeto em um ambiente on-line, bem como fazer atividades com alguns tablets, ultrabook, ou celulares dentro e fora da sala de aula, desenvolvendo narrativas "expansivas", que se conectam com a vida no entorno, com outros grupos e com os interesses profundos dos estudantes.

Tal afirmação vai ao encontro dos resultados de estudos de Bergmann \& Sams (2016), quando afirmam que, nas escolas em que não há recursos tecnológicos sofisticados, podem-se trabalhar projetos com recursos tecnológicos mais simples, como o celular, tecnologia que grande parte dos alunos detém. Nesse sentido, eles estão sempre conectados, podendo estudar e navegar em locais com conectividade aberta e não, necessariamente, na sala de aula ou nos entornos da escola.

Esse tipo de recurso tecnológico contribui para que o aluno tenha flexibilidade para estudar, de modo a se organizar e realizar suas atividades de acordo com sua agenda. Por outro lado, há a necessidade de o aluno ser organizado e comprometido com suas tarefas. Em relação à sala de aula física, entende-se que é o momento em que o aluno tem o contato direto com o professor. Segundo a estrutura dos modelos de ensino híbrido, especificadamente a sala 
de aula invertida, os alunos já devem ter estudado o conteúdo que será abordado durante o encontro presencial via o AVA e, no geral, é atribuída ao encontro presencial uma oportunidade de realizar aprofundamentos teóricos ou simulações de práticas e a oportunidade de tirar dúvidas sobre o que foi estudado anteriormente.

Bergmann \& Sams (2016) ainda destacam que, no modelo tradicional, os alunos normalmente chegam à sala de aula com algumas dúvidas referentes ao dever de casa passado no dia anterior. É comum os professores utilizarem em torno de vinte e cinco minutos, antes do começo da aula, para sanar essas dúvidas e, depois, em torno de quarenta e cinco minutos para apresentar o conteúdo que será desenvolvido em sala. Acreditamos que o professor pode utilizar esse período para trabalhar a prática em laboratório, por exemplo.

Os estudos aqui analisados evidenciam a pertinência do Ensino Híbrido, principalmente quando se objetiva aprofundar os conhecimentos sobre conteúdos e se deseja aplicá-los na resolução de problemas profissionais, uma vez que isso possibilita destinar um tempo maior para desenvolver essas atividades mediadas pelo professor. Cabe relembrar que, nessa modalidade de ensino, anteriormente, os alunos já realizaram o estudo prévio dos conteúdos, cabendo ao professor sanar as dúvidas apresentadas e, na sequência, mediar para que os alunos aprofundem e apliquem esses conhecimentos.

\section{Procedimentos Metodológicos}

Esta pesquisa é de natureza qualitativa. Flick (2009) destaca que a principal característica do método qualitativo é o fato de o pesquisador mergulhar fundo no campo a fim de se tornar um membro desse ambiente, de modo a influenciar, uma vez que ele é um participante. Para entender esse método de pesquisa, o autor sugere dois aspectos: o primeiro diz respeito ao professor se tornar cada vez mais um participante e o segundo incide sobre a participação, pois é de extrema importância que ela se torne mais concreta no sentido de focar os aspectos essenciais relacionados à investigação.

Todavia, nossa participação foi além do definido na pesquisa qualitativa, por isso optamos pela observação participante e, para fundamentá-la, buscamos referências nos estudos de Atkinson \& Hammersley (2005) e Correia (2009). Atkinson \& Hammersley (2005) a considera um método de pesquisa em que o pesquisador participa diretamente do procedimento da pesquisa. É um método que, segundo esses autores, possibilita acrescentar maiores informações a situações e eventos comuns. Todavia, apesar de essa possibilidade ampliar o espectro da coleta, sabíamos, com base em Correia (2009), que tal escolha 
pressupunha a preparação do pesquisador para exercer o papel de observador participante. Correia (2009) afirma que, como método de pesquisa, a Observação Participante requer treino disciplinado, uma boa preparação e requer do observador investigado alguns atributos fundamentais: atenção, sensibilidade e paciência.

Para tanto, foi necessário um preparo anterior à aula: realizar um estudo do conteúdo que o professor aplicaria na aula; utilizar um caderno de campo em que seriam anotados os principais tópicos interessantes do conteúdo para uma análise do processo de observação, assim como as interações envolvendo alunos, professor e conteúdo.

Escolheu-se essa metodologia por considerar que ela possibilitaria coletar informações em tempo real, sem a necessidade de realizar uma entrevista com os alunos e com o professor para entender o processo do ensino híbrido.

\section{Descrição das Aulas Observadas}

Acompanhamos algumas aulas da disciplina Ética, Política e Sociedade ministradas para uma turma do $8^{\circ}$ semestre do Curso de Administração de uma faculdade de Ensino Superior privada, situada no Distrito Federal.

O docente responsável iniciou as aulas apresentando aos alunos uma situaçãoproblema que constituía um desafio referente ao mercado de trabalho por se tratar, de acordo com o professor, de uma necessidade importante nas empresas. Como estávamos em um contexto de ensino híbrido, especificamente uma sala de aula invertida, os alunos deveriam ter realizado seus estudos de pré-aula no AVA, onde os materiais didáticos eram disponibilizados antes da aula presencial.

O desafio entregue aos alunos referia-se à história de um empreendedor que necessitava realizar uma campanha de marketing, na qual os produtos e serviços comercializados deveriam ser apresentados ao público-alvo. Diante desse contexto, os alunos foram desafiados a criar uma campanha utilizando os conhecimentos advindos do conteúdo da disciplina observada.

Pode-se observar que a atividade realizada em sala de aula presencial era um desafio, ou seja, a proposição da resolução de uma situação-problema em grupo. Assim como Bergmann \& Sams (2016), compreendemos que, nos momentos presenciais, para haver situações que promovam o aprofundamento, é de extrema importância que seja construído um contexto em que aluno e professor possam se engajar com o intuito de aplicar e aprofundar os conhecimentos advindos dos estudos realizados com o material disponibilizado no Ambiente 
Virtual. Dessa forma, faz-se necessário assumir uma concepção de problema para que se tenha clareza do tipo de situação que se quer proporcionar em sala de aula.

Onuchic \& Allevato (2012, p.240) afirmam o seguinte: “[há] diferentes concepções de problema. Para nós, é tudo aquilo que não sabemos fazer, mas estamos interessados em fazer". Pode-se notar que essa concepção traz aspectos subjetivos para designar o que é problema, o que denota que a caracterização está na relação que o aluno estabelece com a situação em debate. Pensando no planejamento da aula, o professor precisa mobilizar conhecimentos profissionais, designados por Alarcão (2011, p.68, grifos da autora) como conhecimento do aluno e suas características.

Sendo o aluno o elemento central da ação educativa, é imprescindível que o professor detenha conhecimento do aluno e das suas características, isto é, compreenda o seu passado e o seu presente, a sua história de aprendizagem, o seu nível de desenvolvimento, a sua envolvente sociocultural.

Dessa maneira, podemos concluir que, na elaboração de situações-problema a serem debatidas em momentos presenciais nas aulas híbridas, é preciso levar em conta a necessidade de despertar nos alunos motivação para resolvê-las. Nesse contexto, compreendemos que o uso de contextos profissionais, simulando situações da futura prática profissional, é uma possibilidade de engajar o aluno nos processos de ensino e aprendizagem.

Cabe destacar que, antes da realização da situação-problema, o professor, brevemente, discutiu com os alunos o conteúdo disponibilizado no ambiente virtual de aprendizagem, tirando todas as dúvidas dos conceitos de marketing, estudo mercadológico e outras que haviam sido levantadas.

Na sequência da aula, percebemos que todos os alunos participaram ativamente do desafio proposto pelo professor, sem muita dificuldade e resistência. Interpretamos que a participação dos alunos foi fomentada por terem estudado o conteúdo previamente disponibilizado no ambiente virtual de aprendizagem e que, em sala de aula, estavam prontos para participar da solução do problema apresentado pelo professor. Os alunos dividiram-se em três grupos e, durante um tempo, discutiram como poderiam realizar a campanha publicitária. Em cada grupo havia um aluno mediando as discussões, uma espécie de líder. Nas falas dos alunos, pôde-se identificar conceitos advindos da disciplina Ética, Política e Sociedade, em conjunto com as ferramentas de marketing, conforme podemos observar no neste trecho sobre o grupo 1 retirado das anotações do caderno de campo: 
Research, Society and Development, v. 9, n. 7, e462974332, 2020

(CC BY 4.0) | ISSN 2525-3409 | DOI: http://dx.doi.org/10.33448/rsd-v9i7.4332

Líder: Então, podemos desenvolver uma campanha publicitaria, em forma de vídeo, que apresentaremos a nossa empresa, mas, não falaremos diretamente sobre a empresa, vamos focar na questão da ética, da importância do respeito entre as pessoas quando estão se encontrando, assim, teremos uma visibilidade de que a empresa se preocupa com a questão da ética social (CADERNO CAMPO, 2019).

Na disciplina de Ética, Política e Sociedade, os alunos estudaram sobre valores morais, princípios, ideias do comportamento humano na sociedade e formas de comunicação. Como eram alunos de Administração, tiveram o desafio de resolver a situação-problema envolvendo a temática de marketing. Foi uma atividade na qual os alunos compartilharam várias ideias, construindo um cenário de aprendizagem. Como uma parcela dos alunos atuava em diferentes frentes profissionais, eles apresentavam situações de suas práticas experienciais na atividade proposta pelo professor. $\mathrm{O}$ engajamento esteve muito presente. Um grupo levantou a hipótese de que a campanha publicitária precisaria acatar as necessidades do campo mercadológico em que se constituiria, o que foi muito interessante, pois tinha sido uma aprendizagem que constava no conteúdo disponibilizado no AVA.

Foi possível identificar que os alunos mobilizaram os conteúdos disponíveis no AVA, demonstrando facilidade na resolução do problema. Um dos grupos, na finalização da explicação do professor, levantou o exemplo de uma propaganda de fastfood, vista na televisão, que abordava conceitos da disciplina, pois apresentava o conceito de família. Analisando a exposição do segundo o grupo, notamos que a campanha publicitária não apresentou o produto que estavam comercializando, apenas a interação da família em uma sala de jantar. Entenderam que a empresa de fastfood estava preocupada com a humanização familiar, um dos conceitos da disciplina de Ética, Política e Sociedade estudado no ambiente virtual de aprendizagem.

Como a disciplina foi concebida de acordo com o ensino híbrido, pôde-se observar que, na aula presencial, o professor se limitou a problematizar e a sanar as dúvidas dos alunos e, na sequência, a mediar a resolução do desafio de cunho profissional apresentado. Dessa forma, a aprendizagem dos alunos não se restringiu aos conceitos teóricos, mas englobou, também, sua aplicação em situações práticas. Nesse contexto, consideramos, assim como Bergmann \& Sams (2016), que os alunos e professores tiveram um período maior para discutir e refletir sobre as questões da ética envolvidas na situação prática apresentada.

Após inúmeras discussões colaborativas, ficou evidente que os alunos levantaram exemplos vistos em propagandas de marketing em televisão, outdoors, rádio, Internet e outros meios de comunicação, um exemplo das reflexões realizadas pelos alunos, de acordo com o 
caderno de campo, é o trecho a seguir.

Professor, eu havia visto um outdoor do MacDonald's onde ele apresentava apenas uma imagem de uma família se abraçando, ou seja, não mostrava a imagem de um hambúrguer, a minha interpretação foi que eles queriam mostrar a questão da responsabilidade social, um tópico presente no conteúdo sobre ética que realizei a leitura ontem (CADERNO DE CAMPO, 2019).

Assim, olhando para suas experiências e para os estudos realizados anteriormente, os estudantes construíram suas propostas. Após esse momento, todos realizaram a apresentação dos seus trabalhos para os demais alunos e foram avaliados pelo professor. Observou-se que o estudo conduzido pelo professor em sala de aula, por meio do ensino híbrido, possibilitou o desenvolvimento de habilidades e competências no que diz respeito a encarar os desafios reais encontrados no mercado de trabalho, segmento que estão estudando na disciplina.

É importante enfatizar que, quando se aborda situação-problema em sala de aula sobre desafios apresentados no cenário mercadológico, com lastro no contexto profissional futuro do aluno, desperta-se o seu interesse em participar dessas atividades, uma vez que são casos reais que poderão ser enfrentados por eles em sua futura vida profissional. Quando há momentos de praticar a teoria por meio de situação-problema no ambiente escolar presencial, mediados pelo professor, a construção da aprendizagem tende a ser mais sólida e significativa de modo semelhante ao preconizado por Pereira et al. (2018) e Teixeira et al. (2020). Por outro lado, se apenas a teoria fosse trabalhada nesse momento presencial, algumas das relações estabelecidas entre a teoria e a prática durante a aula poderiam não ocorrer. Chamamos a atenção para o fato de que o tempo destinado a aula presencial é muito pequeno se considerarmos a necessidade de apresentar, discutir e refletir sobre questões teóricas e práticas. Acreditamos que esse modelo de aula promoveu a (re) significação da aprendizagem profissional dos alunos e que é relevante mesclar a teoria disponibilizada no ambiente virtual de aprendizagem com a prática em sala de aula.

\section{Considerações Finais}

De acordo com nossos estudos e com as vivências em sala de aula, entendemos que as configurações de ensino híbrido possibilitam ao professor realizar aprofundamentos do conteúdo e relacioná-los com a futura prática profissional. Trabalhar com situações-problema pode ser uma estratégia para desencadear esses conceitos. Todavia, para que essa relação 
aconteça, é importante que os alunos, em grupos, tenham acesso prévio ao conteúdo em outros locais que não só a sala de aula presencial, tornando-se ativos em seus estudos.

Outro aspecto verificado foi a importância das discussões colaborativas, pois, nessas discussões, os alunos podem mobilizar os conteúdos que estavam disponíveis no AVA e, também, outros conteúdos que já possuem. Nessa etapa, o professor tem o papel fundamental de intervir e guiar para que essas discussões e reflexões ocorram e levem os alunos a construírem conhecimento no contexto de aprendizagem, em ambientes diferenciados, em lugares fora da sala de aula, por meio das tecnologias digitais, conectado à Internet, buscando outras fontes de estudo, em um movimento de complementação.

A participação como observador nas aulas no Curso de Administração possibilitou ao pesquisador obter informações valiosas, que poderão ser estudadas com maior profundidade, principalmente no que tange a outras formas de o professor planejar a sua abordagem a partir da proposição de problemas profissionais, tendo em vista a futura prática profissional dos alunos, a de administrador .

Ao comparar as aulas vivenciadas no modelo tradicional com as aulas observadas, verificamos que a participação dos alunos nestas últimas é diferenciada, conforme ensinam Bergmann \& Sams (2016), pois o protagonismo de sua própria aprendizagem é enfatizado. Isso acarreta mudanças na condução da aula por parte do professor, o que se configura um problema de pesquisa emergente.

Em suma, compreendemos que a sala de aula se transformou em um laboratório de aprendizagem, no qual todos os envolvidos são responsáveis pela construção do seu próprio conhecimento.

Acreditamos que o resultado desta investigação proporcionará aos interessados nas práticas de Ensino Híbrido uma melhor compreensão desse tipo de ensino, que poderão compartilhar com seus alunos. Em um próximo artigo, abordaremos outras práticas de Ensino Híbrido utilizadas nos cursos que acompanhamos ao longo da pesquisa.

\section{Referências}

Alarcão, I. (2011). Professores reflexivos em uma escola reflexiva. ( $8^{\mathrm{a}}$ ed.). São Paulo: Cortez Editora. 
Albino, JP \& Reinhard, N. (1998). Uso potencial da tecnologia da informação no ensino de administração. (Em CD-ROM). In Seminários em Administração - SEMEAD, 3. São Paulo: USP/FEA/PPGA

Aktinson, P \& Hammersley, M. (1998). Ethnography and participant observation. Strategies of Qualitative Inquiry. Thousand Oaks: Sage, 248-261.

Bacich, L, Tanzi Neto, A \& Trevisani, FM. (2015) Ensino Híbrido: Personalização e Tecnologia na Educação. Porto Alegre: Penso.

Bergmann, J \& Sams, A. (2016) Sala de aula invertida: uma metodologia ativa de aprendizagem (A.C.da C. Serra, Trad.). Rio de Janeiro: LTC.

Christensen, CM, Horn, MB \& Staker, H. (2013) Ensino Híbrido: uma inovação disruptiva? Uma introdução à teoria dos híbridos. Recuperado de https://www.pucpr.br/wpcontent/uploads/2017/10/ensino-hibrido_uma-inovacao-disruptiva.pdf.

Correia, MC. (1999). A Observação Participante enquanto técnica de investigação. Pensar Enfermagem, 13(2), 30-36.

Flick, U. (2009) Qualidade na pesquisa qualitativa. Porto Alegre: Artmed.

Onuchic, LR \& Allevato, NSG. (2004). Novas reflexões sobre o ensino-aprendizagem de matemática através da resolução de problemas. In M. A. V. Bicudo \& M. C. Borba (Orgs.), Educação Matemática: pesquisa em movimento. São Paulo: Cortez.

Pereira, AS, Shitsuka, DM, Parreira, FJ \& Shitsuka, R. (2018). Metodologia da pesquisa científica. [e-book]. Santa Maria. Ed. UAB/NTE/UFSM. Acesso em: 10 maio 2020. Disponível em: https://repositorio.ufsm.br/bitstream/handle/1/15824/Lic_Computacao_MetodologiaPesquisa-Cientifica.pdf?sequence $=1$.

Teixeira, RLP, Shitsuka, R, Brito, MLA, Shitsuka, DM \& Silva, PCD (2020). Metodologias ativas. In: Teixeira, RPL et al. (2020). Oficinas de Processamento e de Materiais para Engenharia: livro de resumos. Belo Horizonte: Poisson. Acesso em: 20 maio 2020. 
Disponível em: https://poisson.com.br/2018/produto/oficinas-de-processamento-e-demateriais-para-engenharia-livro-de-resumos/

Valente, JA. (2014) Blended Learning e as mudanças no Ensino Superior: a proposta da sala de aula invertida. Educar em Revista, 4: 79-97.

\section{Porcentagem de contribuição de cada autor no manuscrito}

Luiz Henrique Alves dos Santos - 40\%

Diego Fogaça Carvalho - 30\%

Angélica da Fontoura Garcia Silva - 15\%

Hallynnee Héllenn Pires Rossetto - 15\% 